\title{
UM MÉTODO DE REPRODUÇÃO INDUZIDA PARA O SURUBIM STEINDACHNERIDION MELANODERMATUM (SILURIFORMES, PIMELODIDAE) DO RIO IGUAÇU
}

\section{A METHOD OF INDUCED REPRODUCTION FOR SURUBIM STEINDACHNERIDION MELANODERMATUM (SILURIFORMES, PIMELODIDAE) OF THE IGUAÇU RIVER}

\author{
Luiz Augusto Marques Ludwig ${ }^{1 *}$, Eder Gomes ${ }^{1}$, Roberto Ferreira Artoni ${ }^{2}$ \\ $1^{*}$ Autor para contato: Estação Experimental de Estudos Ictiológicos, Usina Ney Braga \\ (Segredo), Companhia de Energia do Paraná - COPEL Geração, Mangueirinha, PR; \\ e-mail: laludwig@copel.com \\ 2 Universidade Estadual de Ponta Grossa - UEPG, Departamento de Biologia Estrutural, \\ Molecular e Genética, Campus em Uvaranas, Ponta Grossa, PR \\ Recebido para publicação em 05/12/2005 \\ Aceito para publicação em 10/02/2005
}

\begin{abstract}
RESUMO
Esta breve comunicação apresenta os procedimentos rotineiros e adaptados pela Estação Experimental de Estudos Ictiológicos, Usina Ney Braga, da Companhia de Energia do Paraná (COPEL) para a reprodução induzida do peixe surubim do rio Iguaçu (Steindachneridion melanodermatum), Paraná, Brasil. Os alevinos são obtidos pela indução com hormônio hipofisário administrado a machos e fêmeas adultos no período de reprodução entre outubro e dezembro. A desova ocorre após $260 \pm 20$ horas-grau com a fertilização ocorrendo por hidratação dos ovócitos após liberação do líquido espermático sobre os ovócitos a seco. As larvas eclodem após 18 horas em incubação vertical e após 48 horas são transferidas para caixas circulares e escuras com capacidade para mil litros com circulação vertical. São alimentadas com ração com 45\% de proteína bruta. Estas são então transportadas após dois dias para tanques/viveiros de alevinagem (500 larvas $/ \mathrm{m}^{2}$ ) onde recebem ração com $40 \%$ de proteína bruta até atingirem o estádio de alevino (2 a $6 \mathrm{~cm}$ ). Estes são disponibilizados a um programa de recuperação ambiental por repovoamento na bacia do rio Iguaçu nas áreas de ocorrência natural de Steindachneridion melanodermatum.
\end{abstract}

Palavras-chave: bagre, estádio larval, alevino, conservação 


\begin{abstract}
This short communication presents the adapted routine and procedures for the induced reproduction of surubim catfish of the Iguaçu River in the state of Paraná, Brazil, by the Experimental Station of Ichthyological Studies of the Energy Company of Paraná (COPEL). The alevins are obtained by induction, through the administration of the hypophysarie hormone to adult males and females in the reproduction period, between October and December. The spawning occurs after $260 \pm 20$ hour-degree and the fertilization happens by means of ovocyte hydration after the liberation of the spermatic liquid on the dry ovocytes. The larvae emerge after 18 hours in vertical incubation, and after 48 hours they are transferred into dark circular containers with a capacity for a thousand liters and with vertical circulation. They are fed $45 \%$ crude protein. After two days they are again transferred to an alevin tank/nursery (500 larvae/m2) where they receive a ration of $40 \%$ crude protein until they reach the alevin stadium $(2$ to $6 \mathrm{~cm}$ ). These alevins are made available in a program of environmental recovery for the repopulation of the o Iguaçu River basin, in the areas of natural occurrence of Steindachneridion melanodermatum.
\end{abstract}

Key words: catfish, larval stadium, alevin, conservation

\section{Introdução}

A ictiofauna da América do Sul é a mais rica e diversa do mundo, com uma expectativa de mais de 8000 espécies (Schaefer, 1988). Muito desta fauna ainda é pouco conhecida em diferentes aspectos da suabiologia.

A exploração comercial de peixes tem-se desenvolvido sobremaneira com o avanço das tecnologias de reprodução e larvicultura, principalmente em relação às espécies exóticas como a tiápia (Oreochromis niloticus) e a carpa (Cyprinus carpio). Especialmente em relação às espécies nativas os avanços na produção têm sido mais recentes. Destaca-se a criação em cativeiro de espécies de Characiformes como o curimba (Prochilodus lineatus), piau (Leporinus friderici) e mais recentemente de grandes bagres pimelodídeos como o pintado (Pseudoplatystoma corruscans).

Estudos recentes têm procurado conciliar técnicas adequadas que promovam um máximo de aproveitamento zootécnico das espécies nativas, e que possibilitam programas de conservação dessas espécies.

A ocorrência de uma nova espécie de
Steindachneridion (Steindachneridion sp. melanodermatum) endêmica a bacia do rio Iguaçu, foi registrada pela primeira vez por Garavello (1991), confirmada por Severi e Cordeiro (1994) e recentemente descrita por Garavello (2005) como Steindachneridion melanodermatum (Figura 1a) Os surubins do gênero Steindachneridion são grandes bagres pimelodídeos de hábito carnívoro de interesse para a pesca e para a piscicultura (Zaniboni Filho et al., 2004). O surubim (Steindachneridion melanodermatum) é um peixe reofílico (migrador) em pelo menos uma das fases da vida (Agostinho et al., 1997) e, portanto, para o processo reprodutivo necessita da indução por homônimos gonadotróficos e hipofisários para o amadurecimento terminal das gônadas masculinas e femininas.

O presente trabalho relata a experiência da Estação Experimental de Estudos Ictiológicos (EEEI) da Usina Ney Braga (Segredo), Companhia Paranaense de Energia (COPEL), em técnicas de reprodução e alevinagem do surubim do Iguaçu (Steindachneridion melanodermatum) desde a década de 90. 


\section{Material e métodos}

Os exemplares de Steindachneridion melanodermatum utilizados no programa de reprodução induzida foram capturados em 1998 na bacia do baixo rio Iguaçu, Usina José Richa, município de Capitão Leônidas Marques, Paraná e constituem um plantel de cerca de 500 exemplares. Estes exemplares variam em tamanho e peso, sendo considerado para a reprodução aqueles com mais de $30 \mathrm{~cm}$ de comprimento padrão e $1.000 \mathrm{~g}$ de peso total. O plantel é mantido em tanques de criação de $1.000 \mathrm{~m}^{2}$ e $2,8 \mathrm{~m}$ de profundidade com $30 \mathrm{~cm}$ de terra vegetal no fundo e adubação anual com esterco de carneiro ou gado, separados para machos e fêmeas. Estes animais são alimentados uma vez por dia com ração de superfície enrriquecida com $40 \%$ de proteína animal até o mês de julho na proporção de $1 \%$ do peso vivo. Após intensifica-se a dieta com até $3 \%$ do peso vivo até o período reprodutivo.

No presente relato foram utilizados quatro exemplares fêmeas com média de peso de $5 \mathrm{~kg}$ por animal e dois machos com média de peso de $2.500 \mathrm{~g}$ por animal. Após aclimatação em tanques menores de 1.000 litros/animal a temperatura de $\pm 27^{\circ} \mathrm{C}$ os animais são anestesiados com benzocaína 1\% e pesados para o cálculo de administração do extrato hipofisário na proporção de 0,5mg/Kg em machos e fêmeas e 5,0mg/ Kg nas fêmeas após 10 horas da primeira aplicação. No momento em que as fêmeas recebem a segunda dosagem hormonal os machos recebem uma dose única de $0,5 \mathrm{mg} / \mathrm{Kg}$.

Após os procedimentos de fecundação a seco dos óvulos extrusados em um Becker ou vasilha de plástico com a adição de líquido espermático e hidratação subseqüente, os animais são tratados profilaticamente em banho de imersão em cloreto de sódio $0,9 \%$ por 3 minutos antes de retornarem aos viveiros de criação.

\section{Resultados e discussão}

Os animais selecionados para a indução hormonal foram os adultos e aptos à reprodução. Nas fêmeas observa-se o volume abdominal, flacidez da região ventral e papila urogenital hiperemiada (bem irrigada de sangue), enquanto nos machos se observa a fluidez do sêmen. Freqüentemente animais com mais de um ano de vida e $1000 \mathrm{~g}$ já atingiram a maturidade sexual. Em princípio a constituição de um bom plantel de matrizes e reprodutores deve ser considerado para a manutenção e manejo em cativeiro. Esta providencia é primordial para programas que visam à manutenção da variabilidade genética para a produção e conservação ex situ e in situ das espécies de peixes nativos. Assim, animais utilizados em um ciclo de propagação artificial são poupados no próximo período reprodutivo, e os problemas com retrocruzamentos são minimizados.

Após a seleção das matrizes e reprodutores aptos, entre os meses de outubro e dezembro, mantémse os animais numa densidade de 1000 litros por indivíduo sob temperatura controlada $\left( \pm 27^{\circ} \mathrm{C}\right)$ até aclimatação e em seguida o extrato hipofisário foi administrado intra-muscularmente na base das nadadeiras peitorais com seringa e agulha hipodérmicas. As fêmeas receberam duas doses de hormônio por quilograma de massa corpórea, sendo 0,5mg e 5,0mg/ $\mathrm{kg}$ com intervalo de tempo de 10 horas. No momento em que as fêmeas receberam a segunda dosagem hormonal os machos receberam uma dose única de $0,5 \mathrm{mg} / \mathrm{kg}$. As papilas genitais se diferenciaram após 12 horas aproximadamente após a indução, sendo a papila genital das fêmeas de aspectos mais arredondado do que a papila dos machos (Figura 1b e 1c).

A desova, que nesta espécie é total, ocorreu entre $260 \pm 20$ horas-grau e os ovos, de aspecto hialino (Figura 1d) foram fertilizados a seco por 1 a 2 minutos e depois incubados em incubadoras de fluxo de água vertical, onde a eclosão ocorreu após 18 horas. Segundo Nakatani et al. (2001), os ovos recémfecundados apresentam diâmetro médio de 3,02mm.

O saco vitelínico foi absorvido em 48 horas e então as larvas (Figura 1e) foram transferidas para caixas circulares e escuras com capacidade para mil litros com circulação vertical. Neste estádio do desenvolvimento, o canibalismo foi bastante intenso e, portanto, a alimentação com ração enriquecida com 45\% de proteína bruta de origem animal e misturada a fígado de boi triturado e diluído em água $(1: 1 \mathrm{v} / \mathrm{v})$, que foi administrada a cada 2 horas no período diurno e uma única vez no período noturno, se constituiu em importante medida para o sucesso na sobrevivência 
das larvas de surubim. Estas não apresentam pigmentação nos estádios iniciais de vida, o que só ocorre após o estágio de flexão (Nakatani et al., 2001).

A temperatura desta segunda etapa da larvicultura foi mantida ao redor dos $27^{\circ} \mathrm{C}$, por dois dias e no escuro, com as caixas tampadas. Esta providência também diminuiu a predação entre as larvas.

Após, as larvas foram transferidas para tanques/ viveiros de criação adubados química e organicamente para a produção de plâncton em uma densidade de 500 larvas $/ \mathrm{m}^{2}$ onde passaram a receber ração extrusada enriquecida com $40 \%$ de proteína bruta de origem animal até atingirem o estádio de alevino ( 2 a $6 \mathrm{~cm}$ Figura 1f). Em seguida estes peixes foram destinados ao programa de repovoamento de locais de ocorrência natural de surubim na bacia do rio Iguaçu.

Com as atividades periódicas de amostragem da ictiofauna do rio Iguaçu, realizada pela COPEL em seus lagos de inundação para a geração de energia, tem sido corrente a presença de exemplares de surubins adultos (com mais de 1kg) oriundos da EEEI da Usina Ney Braga onde são obtidos por reprodução induzida anualmente desde 1996.

Destaca-se assim, a importância de conhecer aspectos básicos da biologia das espécies nativas de peixes brasileiros, a exemplo da sua reprodução, para a manutenção e recuperação da diversidade e riqueza destas espécies.

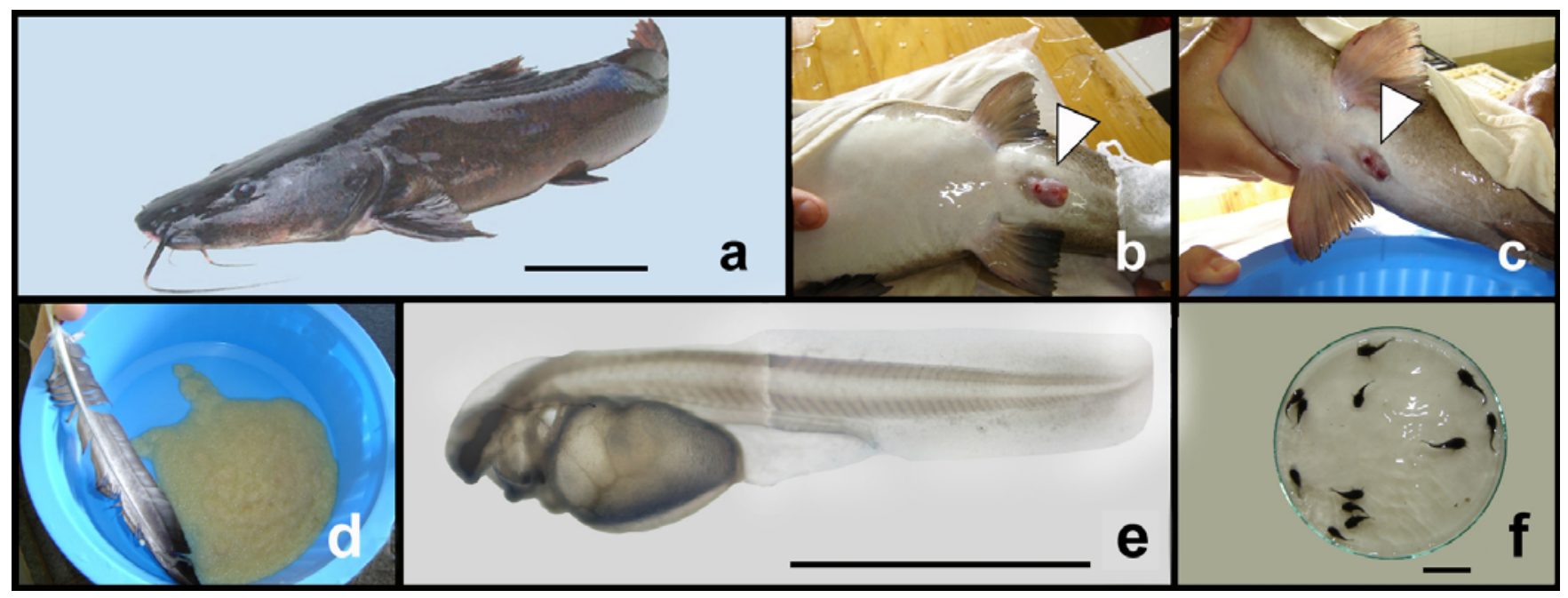

Figura 1 - (a) Surubim do rio Iguaçu (Steindachneridion melanodermatum). A barra de escala corresponde a $10 \mathrm{~cm}$. Detalhe da papila genital de fêmea (b) e macho (c) de surubim. (d) desova de fêmea de surubim. (e) Larva recém eclodida de surubim (f) e alevino se surubim com 15 dias. As barras de escala correspondem a 0,3 cm e 2,0 cm, respectivamente.

\section{Agradecimentos}

Os autores são gratos ao IAP(Instituto Ambiental do Paraná), IBAMA (Instituto Brasileiro do Meio Ambiente) e ao CNPq (Conselho Nacional de Desenvolvimento Científico e Tecnológico). Este trabalho teve suporte financeiro da Companhia Paranaense de Energia - COPEL Geração. Os autores são particularmente gratos aos técnicos e funcionários da Estação Experimental de Estudos Ictiológicos da Usina Ney Braga (Segredo).

\section{REFERÊNCIAS}

1. AGOSTINHO, A.A.; JÚLIO JÚNIOR, H.F.; GOMES, L.C.; BINI, L.M.; AGOSTINHO, C.S. Composição, abundância e distribuição espaço-temporal da ictiofauna. In: VAZZOLER, A.E.A. de M.; AGOSTINHO, A.A.; HAHN, N.S. (Eds). A planície de inundação do alto rio Paraná: aspectos físicos, biológicos e socioeconômicos. Maringá, 1997. p. 179-208.

2. GARAVELLO, J.C. Revisão do gênero Steindachneridion Eigenmann \& Eigenmann 1919 (Pisces, Ostariophysi, Pimelodidae). XVIII Congresso Brasileiro de Zoologia, Salvador, 24 fev.-01 marc., (Livro de resumos). 1991. 
3. GARAVELLO, J.C. Revision of genus Steindachneridion (Siluriformes: Pimelodidae). Neotropical Ichthyology, 3(4):607623, 2005.

4. NAKATANI, K.; AGOSTINHO, A.A.; BAUMGARTNER, G.; BIALETZKI, A. SANCHES, P.V.; MAKRAKIS, M.C.; PAVANELLI, C.S. Ovos e larvas de peixes de água doce: desenvolvimento e manual de identificação. Maringá: EDUEM, 2001.378p.

5. SCHAEFER, S. A. Conflict and resolution: Impact of new taxa on phylogenetic studies of the neotropical cascudinhos
(Siluroidei: Loricariidae). In: MALABARBA, L.R.; REIS, R.E.; VARI, R.P.; LUCENA, Z.M.S.; LUCENA, C.A.S. (Eds.). Phylogeny and classification of neotropical fishes. Porto Alegre, Edipucrs, 1998. p. 375-400.

6. SEVERI, W.; CORDEIRO, A.A.M. Catálogo de peixes da bacia do rio Iguaçu. Curitiba: IAP/GTZ, 1994. 128p.

7. ZANIBONI FILHO, E.; MEURER, S.; SHIBATTA, O.A.; NUÑER, A.P. de O. Catálogo ilustrado de peixes do alto rio Uruguai. Florianópolis: Ed. Da UFSC: Tractebel Energia, 2004. 128p. 